\title{
Research on Parameter Extraction Method of Photovoltaic Module Based on Improved Hybrid Algorithm
}

\author{
Haitao $W u \mathbb{D}^{1,2}$ and Zhou Shang ${ }^{3}$ \\ ${ }^{1}$ School of Robot Engineering, Yangtze Normal University, Chongqing 408100, China \\ ${ }^{2}$ School of Electrical Engineering, Chongqing University, Chongqing 400044, China \\ ${ }^{3}$ Xingzhi Primary School of Shenzhen City, Shenzhen 518013, China \\ Correspondence should be addressed to Haitao Wu; wht29@163.com
}

Received 14 June 2019; Revised 13 November 2019; Accepted 12 December 2019; Published 13 January 2020

Academic Editor: Giulia Grancini

Copyright (C) 2020 Haitao Wu and Zhou Shang. This is an open access article distributed under the Creative Commons Attribution License, which permits unrestricted use, distribution, and reproduction in any medium, provided the original work is properly cited.

\begin{abstract}
Correct extraction of the equivalent circuit model parameters of photovoltaic modules is of great significance for power prediction, fault diagnosis, and system optimization of photovoltaic power generation systems. Although there are many methods developed to extract the equivalent circuit model parameters of the photovoltaic module, it is still challenging to ensure the stability and operational efficiency of the extract method. In order to effectively extract the parameters of photovoltaic modules, this paper proposes a hybrid algorithm combining analytical methods and differential evolution algorithms for the extraction parameters of PV module. Firstly, the analytical method is applied to simplify the equivalent circuit model and improve the efficiency of the algorithm. Then, the adaptive algorithm is used to adjust the parameters of the differential evolution algorithm. Through the algorithm proposed in this paper, the parameters of the equivalent circuit model of the photovoltaic module can be extracted by the open-circuit voltage, short-circuit current, and maximum power point current and voltage provided by the manufacturer. The proposed method is applied to the extraction of the parameters of the dual-diode equivalent circuit model of different types of photovoltaic modules. The reliability and computational efficiency of the proposed algorithm are verified by comparison and analysis.
\end{abstract}

\section{Introduction}

With the emphasis on environmental and energy issues, photovoltaic power generation technology is widely used. In order to predict the power generation of photovoltaic power generation systems [1-5], improve the performance of photovoltaic modules, and perform fault diagnosis [6-10], extracting model parameters based on an equivalent circuit model of photovoltaic modules has become one of the research hotspots [11-13].

The simulation models of solar cells currently widely used include single-diode models and two-diode models [14]. Traditional photovoltaic module modeling uses singlediode models. In recent years, with the deepening of research, researchers have found that the two-diode model takes into account the composite effect of the electrically neutral region and the space charge region, revealing the working mecha- nism of photovoltaic cells, making the two-diode model more accurate than the single-diode model [15]. However, the equivalent circuit model of the PV module based on the two-diode model is implicitly nonlinear. In equation, it is difficult to find the analytical solution by a traditional algebraic method. In recent years, researchers have proposed a large number of modeling methods of this problem. These methods can be divided into two categories: one is the numerical solution method, and the analytical solution to the model is obtained through some empirical formulas and mathematical techniques. It is shorter, because the method usually ignores some parameters or uses empirical formulas to obtain some parameters. If the parameters are improperly set in the application process, it will affect the accuracy of the modeling [16-19]. The other type uses the intelligent optimization algorithm, such as the differential evolution (DE) algorithm, particle swarm optimization 
(PSO) algorithm, and genetic algorithm (GA). These methods do not approximate the parameters during use, which can improve the accuracy of the solution [20-27]. However, these intelligent optimization algorithms are random optimization algorithms. If the algorithm parameters are set incorrectly, it will affect the stability and robustness of the solution. In addition, these algorithms take a long time to solve high-dimensional optimization problems. There are also two sources of data for PV module modeling. One is the $I-V$ data of a PV module obtained under experiment under certain conditions; the other is the standard test condition (STC) provided by the manufacturer: short-circuit current, open-circuit voltage, and voltage and current at the maximum power point. The first type of data comes from experiments. The established model is close to the actual working conditions, but the experimental workload is large, and the test process data will error due to the limitations of the test conditions, resulting in a large model error. The second is data. Standard test data from manufacturers are reliable data source, have small modeling workload, and are widely used in engineering, but this method has a small amount of data; if the modeling method is not appropriate, it will lead to large model error.

To find a fast, simple, and accurate method for modeling solar cells, Chin et al. [28] proposed a hybrid calculation method that combines numerical solutions with intelligent optimization algorithms to extract the parameters of the photovoltaic module circuit model using standard test data provided by the manufacturer. The solution method is used to obtain the photogenerated current in the solar cell model under standard test conditions, the two equivalent diode reverse saturation currents, and the parallel resistance. Then, the differential evolution algorithm is used to find the ideal factor and series resistance of the two diodes. This method combines two modeling methods to achieve fast and accurate modeling of solar cells. However, in order to maintain the accuracy of the modeling, the method does not make any approximations and assumptions in the numerical solution method, which leads to the complexity of the explicit expression of the parameters, which increases the difficulty of modeling and increases the calculation time. In addition, the evolutionary algorithm has the advantages of easy implementation and optimization for multipeak functions. However, in the evolutionary process of random search, the phenomenon of "premature maturity" is easy to occur, which leads to the local best, which leads to the decline of modeling accuracy.

Tao et al. [29] used the adaptive differential evolution algorithm to extract the parameters of the PV module based on the two-diode model, but it is modeled by the $I-V$ data obtained by the experiment, and the dimensionality of the solution is not caused by the dimension reduction processing of the model. It is higher, is more computational, and has time-consuming modeling. The adaptive differential evolution algorithm used in this paper only makes the scaling factor adaptively adjust with evolutionary algebra. Although this method can avoid the phenomenon of "premature," the search efficiency and robustness of the algorithm are not improved much.
In order to maintain the advantages of the differential evolution algorithm and suppress the "premature maturity" phenomenon, researchers at home and abroad have improved the differential evolution algorithm. The improved method can be divided into two types, one is the improvement of the algorithm parameters and steps, such as Qin et al. [30] replacing the contraction factor of the algorithm with a Gaussian random number and randomly selecting an individual to perform mutation operations to improve the robustness and search efficiency of the algorithm. VoDuy et al. [31] in the variation operation, according to the average adaptation of the population to the optimal value, determine the scaling factor. The population adds partial perturbations in the later stages of evolution, maintaining population diversity and avoiding "premature maturity." Another type is to add disturbance factors outside the population, maintain population diversity, and avoid falling into local parts, which is the most advantageous. Tvrdik and Krivy [32] used the best clustering method to select indivitwos involved in evolution, selected individual from different categories to form new populations of the iterative process, and randomly sorted the indivitwos in the cluster center. It searches for the global best. Ayala et al. [33] used the fusion of population information and manual intervention selection process to automatically identify the best search path. Qin and Suganthan [34] combine the above two improved methods, using improved crossover strategy and adaptive adjustment control parameters, to achieve global optimization. In order to improve the performance of the differential evolution algorithm, the researchers improved the traditional differential evolution algorithm in terms of parameter setting and mutation strategy and proposed many improved differential evolution algorithms [33, 35-43]. In this paper, the parameter adaptive method proposed by Civicioglu and Besdok is used to adjust the parameters in the algorithm [33, 35-43].

The aim of this paper is to develop a PV module parameter extraction algorithm that combines the analytical method with the improved differential evolution algorithm. The algorithm can accurately extract the PV module parameters based on the dual-diode circuit model and has higher computational efficiency. In the proposed algorithm, the equivalent circuit model is simplified by the analytical method to improve the efficiency of the algorithm. Then, the adaptive algorithm is used to adjust the parameters in the differential evolution algorithm to avoid the algorithm falling into local optimum and improve the convergence speed. Finally, using the above algorithm and the open-circuit voltage, short-circuit current, and maximum power point current and voltage of the photovoltaic module provided by the manufacturer, the equivalent circuit model parameters of the photovoltaic module can be extracted. The proposed method is applied to the extraction of dual-diode equivalent circuit model parameters of different types of photovoltaic modules. The comparison and analysis indicate that the proposed algorithm has high reliability and competitive computational efficiency.

The main contributions of this paper are as follows: 
(1) A hybrid algorithm combining analytical methods and differential evolution algorithms is developed for PV parameter estimation. In this method, the analytical method is applied to simplify the equivalent circuit model and improve the efficiency of the algorithm

(2) The proposed algorithm employs an adaptive method to adjust the parameters in the differential evolution algorithm to avoid the algorithm getting into the local best and speed up the convergence of the algorithm

(3) The proposed algorithm is applied to extract parameters of three different PV modules. The obtained results of the method proposed in this paper are compared with well-established algorithms to confirm its effectiveness

The rest of the paper is organized as follows: Section 2 introduces the photovoltaic module model based on two diodes. Section 3 describes PV module modeling and parameter optimization problem. Section 4 introduces the principles of the improved differential evolution algorithm. Section 5 presents experimental results and discussion. Section 6 concludes this paper.

\section{The Photovoltaic Module Model Based on Two Diodes}

The model of the photovoltaic module based on the two diodes is shown in Figure 1. Its mathematical model is as shown in equation (1).

$$
\begin{aligned}
I= & I_{\mathrm{PV}}-I_{o 1}\left(e^{\left(V+I R_{s}\right) /\left(N_{s} n_{1} V_{t}\right)}-1\right)-I_{o 2} \\
& \left(e^{\left(V+I R_{s}\right) /\left(N_{s} n_{2} V_{t}\right)}-1\right)-\frac{V+I R_{s}}{R_{\mathrm{sh}}},
\end{aligned}
$$

where $I$ is the output current (A) for the photovoltaic module; $V$ is the output voltage $(\mathrm{V})$ for the photovoltaic module; $I_{\mathrm{PV}}$ is the photogenerated current (A); $I_{o 1}$ and $I_{o 2}$ are the two equivalent diode reverse saturation currents (A), respectively; $n_{1}$ and $n_{2}$ are the ideality factor of the two-diode model; $R_{s}$ is the equivalent series resistance of the photovoltaic cell $(\Omega) ; R_{\mathrm{sh}}$ is the equivalent parallel resistance of the photovoltaic cell $(\Omega)$; and $V_{\text {th }}(T)$ is the thermal temperature coefficient of the photovoltaic cell; its equation is

$$
V_{\mathrm{th}}(T)=\frac{k T}{q},
$$

where $k$ is the Boltzmann constant $\left(1.38 \times 10^{-23} \mathrm{~J} / \mathrm{K}\right), T$ is the absolute temperature $(\mathrm{K})$ for the photovoltaic cell, and $q$ is the electron charge $\left(1.6 \times 10^{-19} \mathrm{C}\right)$.

The short-circuit current $I_{\mathrm{SC}}$, open-circuit voltage $V_{\mathrm{OC}}$, and maximum power point voltage $V_{\mathrm{MPP}}$ and current

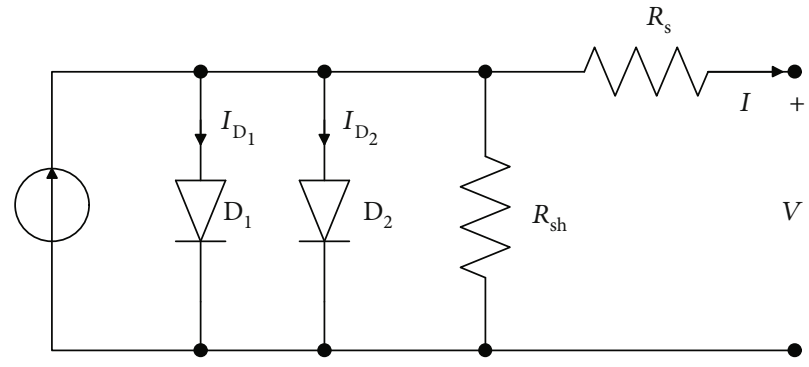

FIgure 1: Two-diode circuit model for the PV module.

$I_{\mathrm{MPP}}$ at different temperatures and different solar radiation intensities can be obtained by the parameters of the standard test conditions provided by the manufacturer and according to

$$
\begin{gathered}
I_{\mathrm{SC}}=I_{\mathrm{SC}, \mathrm{STC}} \frac{G}{G_{\mathrm{STC}}}\left[1+K_{I}\left(T-T_{\mathrm{STC}}\right)\right], \\
V_{\mathrm{OC}}=V_{\mathrm{OC}, \mathrm{STC}}+V_{\mathrm{th}} \ln \frac{G}{G_{\mathrm{STC}}}+K_{V}\left(T-T_{\mathrm{STC}}\right), \\
V_{\mathrm{MPP}}=V_{\mathrm{MPP}, \mathrm{STC}}+V_{\mathrm{th}} \ln \frac{G}{G_{\mathrm{STC}}}+K_{\mathrm{VP}}\left(T-T_{\mathrm{STC}}\right), \\
I_{\mathrm{MPP}}=I_{\mathrm{MPP}, \mathrm{STC}} \frac{G}{G_{\mathrm{STC}}}\left[1+K_{\mathrm{IP}}\left(T-T_{\mathrm{STC}}\right)\right],
\end{gathered}
$$

where $I_{\mathrm{SC}, \mathrm{STC}}, V_{\mathrm{OC}, \mathrm{STC}}, I_{\mathrm{MPP}, \mathrm{STC}}, V_{\mathrm{MPP}, \mathrm{STC}}, G_{\mathrm{STC}}$, and $T_{\mathrm{STC}}$ are the short-circuit current, open-circuit voltage, maximum power point current, maximum power point voltage, solar radiation intensity, and temperature measured under standard test conditions; $K_{I}, K_{V}, K_{I P}$, and $K_{V P}$ are the short-circuit current, open-circuit voltage, maximum power point current, and maximum power point voltage; and $G$ and $T$ are the radiation intensity and temperature of the photovoltaic module. The manufacturer does not provide the seven parameters $I_{\mathrm{PV}}, I_{o 1}, I_{o 2}, n_{1}, n_{2}, R_{s}$, and $R_{\mathrm{sh}}$ contained in equation (1), so the purpose of modeling the PV module was to estimate the above seven parameters from the data provided by the manufacturer. The seven parameters in (1) make the voltage-current curve of the PV module obtained by equation (1) consistent with the measurement curve provided by the manufacturer.

\section{PV Module Modeling and Parameter Optimization}

In this paper, using the test data provided by the manufacturer, combined with the numerical solution method and differential evolution algorithm, a method of modeling and parameter optimization of photovoltaic cells using only PV module test parameters is proposed. 


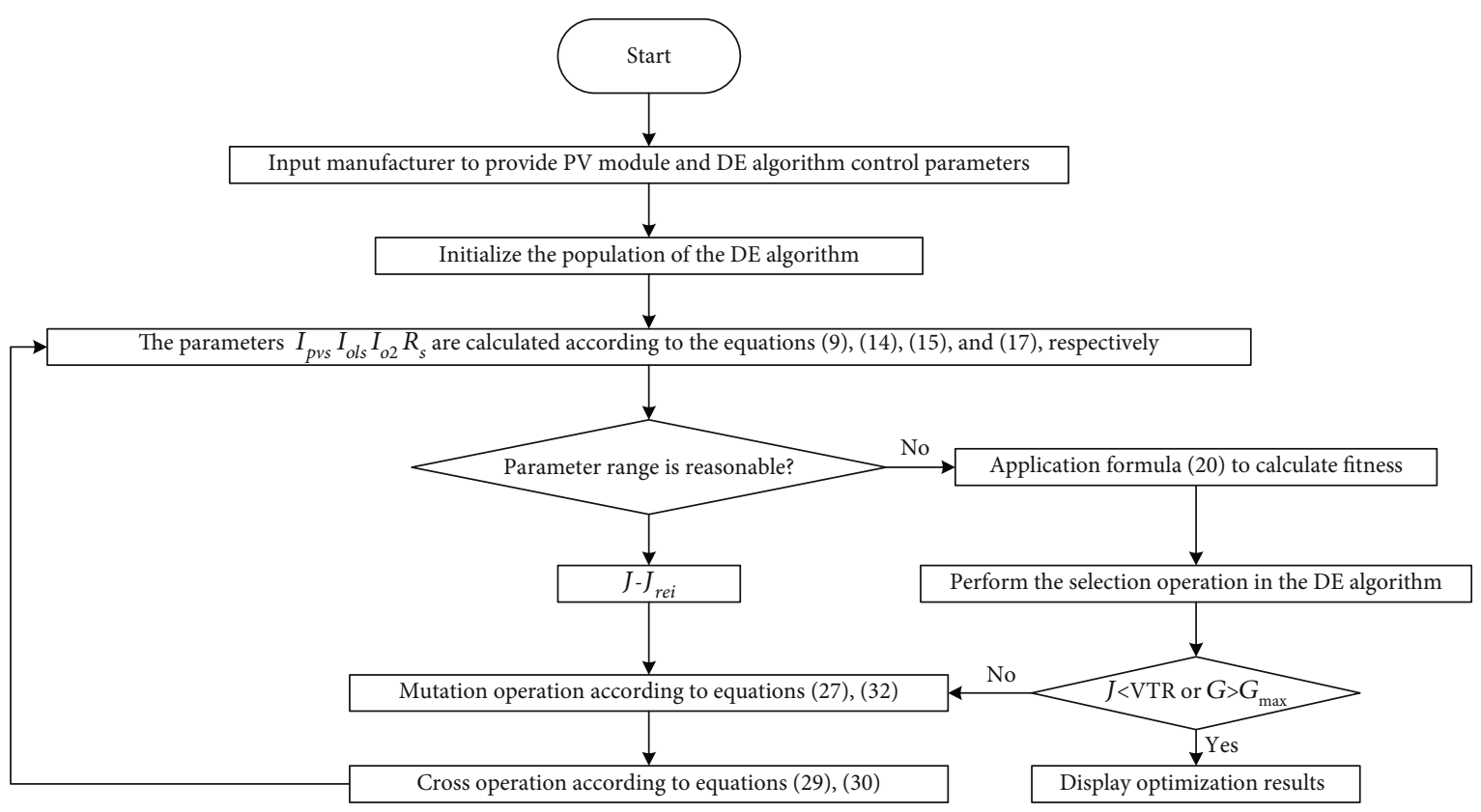

FIGURE 2: The algorithm flow chart proposed in this paper.

First, the manufacturer provides the short-circuit status point data into formula (1):

$$
\begin{aligned}
I_{\mathrm{SC}, \mathrm{STC}}= & I_{\mathrm{PV}, \mathrm{STC}}-I_{o 1, \mathrm{STC}}\left(e^{\left(I_{\mathrm{SC}, \mathrm{STC}} R_{s, \mathrm{STC}}\right) /\left(N_{s} n_{1, \mathrm{STC}} V_{\mathrm{th}, \mathrm{STC}}\right)}-1\right)-I_{o 2} \\
& \left(e^{\left(I_{\mathrm{SC}, \mathrm{STC}} R_{s, \mathrm{STC}}\right) /\left(N_{s} n_{2, \mathrm{STC}} V_{\mathrm{th}, \mathrm{STC}}\right)}-1\right)-\frac{I_{\mathrm{SC}, \mathrm{STC}} R_{s, \mathrm{STC}}}{R_{\mathrm{Sh}, \mathrm{STC}}},
\end{aligned}
$$

where $n_{1 \mathrm{STC}}$ and $n_{2 \mathrm{STC}}$ are the two-diode quality factors in the photovoltaic cell circuit models under standard test conditions, $R_{s, S T C}$ is the equivalent series resistance of the photovoltaic cell under test conditions, $R_{\mathrm{sh}, \mathrm{STC}}$ is the equivalent parallel resistance of the photovoltaic cell under the test conditions, and $V_{\text {th,STC }}$ is the thermal temperature coefficient of the photovoltaic cell under test conditions; the mathematical expression is

$$
V_{\mathrm{th}, \mathrm{STC}}=\frac{k T_{\mathrm{STC}}}{q} .
$$

Normally, $\quad I_{o 1, \mathrm{STC}}\left(e^{\left(I_{\mathrm{SC}, \mathrm{STC}} R_{s, \mathrm{STC}}\right) /\left(N_{s} n_{1, \mathrm{STC}} V_{\mathrm{th}, \mathrm{STC}}\right)}-1\right) \approx 0$, $I_{o 2, \mathrm{STC}}\left(e^{\left(I_{\mathrm{SC}, \mathrm{STC}} R_{s, \mathrm{STC}}\right) /\left(N_{s} n_{2, \mathrm{STC}} V_{\mathrm{th}, \mathrm{STC}}\right)}-1\right) \approx 0, R_{s, \mathrm{ref}}<<R_{p, \text { ref }}$, then equation (1) can be simplified to

$$
I_{\mathrm{PV}, \mathrm{STC}} \approx I_{\mathrm{SC}, \mathrm{STC}} .
$$

Similarly, it is available to substitute the open-circuit voltage state point $\left(V_{\mathrm{oc}, \mathrm{ref}}, 0\right)$ into equation (1):

$$
\begin{aligned}
I_{\mathrm{PV}, \mathrm{STC}} \approx & I_{o 1, \mathrm{STC}}\left(e^{\left(V_{\mathrm{OC}, \mathrm{STC}}\right) /\left(N_{s} n_{1, S T C} V_{\mathrm{th}, \mathrm{STC}}\right)}-1\right)-I_{o 2} \\
& \left(e^{\left(V_{\mathrm{OC}, \mathrm{STC} C}\right) /\left(N_{s} n_{2, \mathrm{STC}} V_{\mathrm{th}, \mathrm{STC}}\right)}-1\right)-\frac{V_{\mathrm{OC}, \mathrm{STC}}}{R_{\mathrm{sh}, \mathrm{STC}}}=0 .
\end{aligned}
$$

Set

$$
\begin{aligned}
X_{\mathrm{OC} i} & =e^{\left(V_{\mathrm{OC}, \mathrm{STC}}\right) /\left(N_{s} n_{i, \mathrm{STC}} V_{\mathrm{th}, \mathrm{STC}}\right)}, \quad i=1,2, \\
X_{\mathrm{MPP} i} & =e^{\left(V_{\mathrm{MPP}, \mathrm{STC}}+I_{\mathrm{MP}, \mathrm{STC} C} R_{s, S \mathrm{TC}}\right) /\left(N_{s} n_{\mathrm{i}, \mathrm{STC}} V_{\mathrm{th}, \mathrm{STC}}\right)}, \quad i=1,2 .
\end{aligned}
$$

According to the analysis of Yahya-Khotbehsara and Shahhoseini [44], in general, $I_{o 2, S T C}$ is three to four times $I_{o 1, \mathrm{STC}}$; it can be expressed by the following formula:

$$
I_{o 2, \mathrm{STC}}=\left(\frac{T^{2 / 5}}{3.77}\right) I_{o 1, \mathrm{STC}} .
$$

Substituting equation (13) into equation (10) and because of the expression that can be obtained

$$
\begin{aligned}
& I_{o 1, \mathrm{STC}} \approx \frac{I_{\mathrm{SC}, \mathrm{STC}}}{\left(X_{\mathrm{OC} 1}-1\right)+\left(T^{2 / 5} / 3.77\right)\left(X_{\mathrm{OC} 2}-1\right)}, \\
& I_{o 2, \mathrm{STC}}=\left(\frac{T^{2 / 5}}{3.77}\right) \frac{I_{\mathrm{SC}, \mathrm{STC}}}{\left(X_{\mathrm{OC} 1}-1\right)+\left(T^{2 / 5} / 3.77\right)\left(X_{\mathrm{OC} 2}-1\right)} .
\end{aligned}
$$


Similarly, substituting the maximum power state point $\left(V_{\mathrm{MPP}, \mathrm{STC}}, I_{\mathrm{MPP}, \mathrm{STC}}\right)$ into equation (1) is available:

$$
\begin{aligned}
I_{\mathrm{MPP}, \mathrm{STC}}= & I_{\mathrm{PV}, \mathrm{STC}}-I_{o 1, \mathrm{STC}}\left(X_{\mathrm{MPP} 1}-1\right)-I_{o 2}\left(X_{\mathrm{MPP} 2}-1\right) \\
& -\frac{V_{\mathrm{MPP}, \mathrm{STC}}+I_{\mathrm{MPP}, \mathrm{STC}} R_{s, \mathrm{STC}}}{R_{\mathrm{sh}, \mathrm{STC}}}
\end{aligned}
$$

$$
R_{s, \mathrm{STC}}=\frac{V_{\mathrm{MPP}, \mathrm{STC}}+I_{\mathrm{MPP}, \mathrm{STC}} R_{s, \mathrm{STC}}}{I_{\mathrm{PV}, \mathrm{STC}}-I_{o 1, \mathrm{STC}}\left(X_{\mathrm{MPP} 1}-1\right)-I_{o 2}\left(X_{\mathrm{MPP} 2}-1\right)-I_{\mathrm{MPP}, \mathrm{STC}}} .
$$

At this point, there are only three unknown parameters in the PV module model: $n_{1, \mathrm{STC}}, n_{2, \mathrm{STC}}$, and $R_{\mathrm{sh}, \mathrm{STC}}$. Effectively reduce the dimension of the differential evolution algorithm to solve the problem. In order to use the differential evolution algorithm to solve the remaining unknown parameters, it is necessary to define a suitable objective function. By observing the $I-V$ curve of the PV module, it can be found that there is a "knee point," that is, the maximum power point, and the position of the maximum power point is affected by three parameters: $n_{1, \mathrm{STC}}, n_{2, \mathrm{STC}}$, and $R_{\mathrm{sh}, \mathrm{STC}}$, so the PV of the PV module can be optimized by optimizing three parameters. The gradient of the curve at the maximum power point is minimal. According to the above analysis, the output power of the maximum power state point is 0 :

$$
\frac{d(I V)}{d V}=I_{\mathrm{MPP}, \mathrm{STC}}+V_{\mathrm{MPP}, \mathrm{STC}} \frac{d I}{d V}=0 .
$$

It can also be written as

$$
\frac{I_{\mathrm{MPP}, \mathrm{STC}}}{V_{\mathrm{MPP}, \mathrm{STC}}}+\left.\frac{d I}{d V}\right|_{\mathrm{MPP}}=0 .
$$

Therefore, the objective function in the differential optimization algorithm is defined as

$$
\begin{aligned}
J & =\left.\left|\frac{I_{\mathrm{MPP}, \mathrm{STC}}}{V_{\mathrm{MPP}, \mathrm{STC}}}+\frac{d I}{d V}\right|\right|_{\mathrm{MPP}}, \\
\left.\frac{d I}{d V}\right|_{\mathrm{MPP}} & =\frac{-I_{o 1, \mathrm{STC}} \alpha_{1} X_{\mathrm{MPP} 1}-I_{o 2, \mathrm{STC}} \alpha_{2} X_{\mathrm{MPP} 2}-1 / R_{\mathrm{sh}, \mathrm{STC}}}{1+I_{o 1, \mathrm{STC}} \alpha_{1} R_{s, \mathrm{STC}} X_{\mathrm{MPP} 1}+I_{o 2, \mathrm{STC}} \alpha_{2} R_{s, \mathrm{STC}} X_{\mathrm{MPP} 2}+R_{s, \mathrm{STC}} / R_{\mathrm{sh}, \mathrm{STC}}},
\end{aligned}
$$

where

$$
\begin{aligned}
& \alpha_{1}=\frac{1}{N_{S} n_{1, \mathrm{STC}} V_{\mathrm{th}, \mathrm{STC}}}, \\
& \alpha_{2}=\frac{1}{N_{S} n_{2, \mathrm{STC}} V_{\mathrm{th}, \mathrm{STC}}} .
\end{aligned}
$$

When applying the differential evolution algorithm to search for, three parameters, in order to ensure that the solution is a feasible solution, the parameter changes must be constrained. According to the literature [11], the constraints are as follows:

When $R_{\mathrm{sh}}<R_{\mathrm{sh}, \min }$, or $R_{\mathrm{sh}}>R_{\mathrm{sh}, \max }$, or $I_{o 1}<0$, or $I_{o 2}<0$, or $I_{o 2}<0$,

$$
J=J_{\text {rej }}
$$

where $R_{\mathrm{sh}, \text { min }}$ and $R_{\mathrm{sh}, \max }$ are the minimum and maximum values of $R_{\mathrm{sh}, \mathrm{STC}}$, respectively. If the parameter search range exceeds the above constraint range, the objective function will be set to $J_{\text {rei }}=10$. Figure 2 is the algorithm flow chart, where VTR is the preset value of the objective function.

\section{Improve Differential Evolution Algorithm}

The differential evolution algorithm is an intelligent optimization algorithm with simple programming and fast convergence. It has strong adaptability to multipeak function optimization problems. It has been optimized in mechanism, image recognition, target tracking, and so on. The field is widely used. With the deepening of human research, the $\mathrm{DE}$ algorithm is also applied to the extraction of PV module parameters. However, since the differential evolution algorithm is a random self-heuristic search algorithm, in highdimensional and multipeak problems, the algorithm will appear "premature," thus falling into the local best. The basic DE algorithm flow is as follows.

4.1. Initialization. The DE algorithm first randomly generates NP $D$-dimensional decision vectors, where the $i$ th vector is expressed as

$$
X_{i, G}=\left[x_{1, i, G}, x_{2, i, G}, x_{3, i, G}, \cdots, x_{D, i, G}\right],
$$

where $G$ is the current algebra and $D$ is the dimension of the vector.

Each element in the vector is randomly generated according to

$$
X_{j, i, G}=X_{L}+\operatorname{rand}[0,1]\left(X_{H}-X_{L}\right),
$$


where $X_{H}$ and $X_{L}$ are the upper and lower bounds of the search space, respectively, and rand $[0,1]$ is a random number that is uniformly distributed between 0 and 1 .

4.2. Mutation Operation. Individuals are randomly selected in the current population, and the mutated individuals are generated by the scaling operation, thereby realizing the search for different regions in the feasible domain. The mutation formula is

$$
V_{i, \mathrm{Gen}}=X_{r_{1}, \mathrm{Gen}}+F\left(X_{r_{2}, \mathrm{Gen}}-X_{r_{3}, \mathrm{Gen}}\right) \text {, }
$$

where $r_{1}, r_{2}$, and $r_{3}$ are random integers, and $r_{1} \neq r_{2} \neq r_{3}$.

4.3. Cross Operation. In order to maintain the diversity of the population, the mutated individuals are exchanged with the original individual information to generate new individuals. The crossoperating operator can be expressed as

$$
U_{j, i, \mathrm{Gen}}= \begin{cases}V_{j, i, \mathrm{Gen}}, & \text { if }\left(\operatorname{rand}[0,1] \leq \mathrm{CR} \text { or } j=j_{\text {rand }}\right), \\ X_{j, i, \mathrm{Gen}}, & \text { otherwise, }\end{cases}
$$

where $j_{\text {rand }}$ is a random number in $[1, D]$, ensuring that at least one of the candidate individuals is from the information of the mutated individual, preventing the occurrence of invalid evolution. At the same time, the individual values are also constrained in the crossover operation. Avoid crossing the boundary and producing nonfeasible solutions.

4.4. Select Operation. Comparing the appropriateness of the original individual and the candidate individual, select the moderately good individual to enter the next iterative process, so as to optimize the decision variable. The selection operator is as in

$$
X_{i, \mathrm{Gen}}= \begin{cases}U_{i, \mathrm{Gen}}, & \text { if } J\left(U_{i, \mathrm{Gen}}\right)<J\left(X_{i, \mathrm{Gen}}\right), \\ X_{i, \mathrm{Gen}}, & \text { otherwise. }\end{cases}
$$

Although the basic differential evolution algorithm has a fast convergence speed, its stability and robustness are poor. In order to maintain the fastness of the parameter optimization process and maintain good stability, literature [45] proposed an adaptive differential evolution algorithm, in which the scaling factor, crossover probability, and optimization strategy can be adaptively selected according to the objective function information to improve the performance of the algorithm. The scaling factor and crossfactor generation probability of each individual obey the Cauchy distribution and the normal distribution. The parameter success rate of the last iteration adjusts the control parameters of the probability distribution model so that the parameters are adaptively adjusted and the performance of the differential evolution algorithm is improved.

The specific method of parameter adaptive adjustment is as follows.
For an individual, its crossover probability $\mathrm{CR}_{i}$ follows a normal distribution:

$$
\mathrm{CR}_{i}=\min \left(\max \left(\operatorname{rand} n_{i}\left(\mu_{\mathrm{CR}}, 0.1\right), 0\right), 1\right) .
$$

In the formula, the effect of $\min (\cdot)$ and $\max (\cdot)$ is to limit CR to $[0,1]$, the initial value of $\mu_{\mathrm{CR}}$ is 0.5 , and it is updated after each iteration:

$$
\mu_{\mathrm{CR}}=(1-c) \cdot \mu_{\mathrm{CR}}+c \cdot \operatorname{mean}_{\mathrm{A}}\left(S_{\mathrm{CR}}\right),
$$

where $S_{\mathrm{CR}}$ is a successful set of crossover probabilities, $\operatorname{mean}_{\mathrm{A}}(\cdot)$ is the arithmetic mean operation, and $c$ is the weighting factor. The scaling factor $F$ is generated as follows:

$$
F_{i}=\min \left(\max \left(\operatorname{rand} c_{i}\left(\mu_{F}, 0.1\right), 0\right), 1\right) .
$$

In the formula, the initial value of $\mu_{F}$ is set to 0.5 and is updated as follows after each iteration:

$$
\mu_{F}=(1-c) \cdot \mu_{F}+c \cdot \operatorname{mean}_{\mathrm{L}}\left(S_{F}\right),
$$

where $\operatorname{mean}_{\mathrm{L}}(\cdot)$ is the Lehmer mean, calculated as

$$
\operatorname{mean}_{\mathrm{L}}\left(S_{F}\right)=\frac{\sum_{F \in S_{F}} F^{2}}{\sum_{F \in S_{F}} F} .
$$

\section{Experimental Results and Discussion}

In order to effectively extract the parameters of the PV module, the parameter setting of the differential evolution algorithm is very important. In Reference [28], the scaling factor and the initial value of the crossover probability are set to 0.5 and 0.8 , respectively. The choice of the crossover strategy is in the literature [28]. For the adaptive selection method, the search range of decision variables is as follows: $n_{1} \in[0.5,2], n_{2} \in[2,4]$, and $R_{s} \in[0.01,3]$; the size of the population is set to 30 ; and the maximum number of iterations is set to 1000 .

In order to verify the proposed method, three different photovoltaic modules were selected, including monocrystalline silicon components, polycrystalline silicon components, and thin film components. The parameters were extracted and compared by different methods. The test data was obtained from the manufacturer's instructions. The parameters of the three components provided by the manufacturer under STC are shown in Table 1. Under the MATLAB platform, the parameters in the diode model corresponding to the three components are extracted by the differential evolution (DE) algorithm [28] and the improved differential evolution (IDE) algorithm proposed in this paper, respectively. In order to make a fair comparison between the algorithm proposed in this paper and the algorithm in the literature [28], the two algorithms were run independently 30 times each to obtain their statistical results. Table 2 shows the statistical results of the experiment. The convergence curves of the two algorithms are shown in Figure 3. The parameters are shown in Tables 3-5. These tables show that the method 
TABLE 1: Parameters of three kinds of PV module.

\begin{tabular}{lcccc}
\hline Parameter & Unit & SP75 & S25 & ST36 \\
\hline ISC,STC & $\mathrm{A}$ & 4.8 & 1.5 & 2.68 \\
VOC,STC & $\mathrm{V}$ & 21.7 & 21.4 & 22.9 \\
IMPP,STC & $\mathrm{A}$ & 4.4 & 1.45 & 2.28 \\
VMPP,STC & $\mathrm{V}$ & 17 & 16.5 & 15.8 \\
KI & $\mathrm{mA} /{ }^{\circ} \mathrm{C}$ & 2 & 0.7 & 0.32 \\
$\mathrm{KV}$ & $\mathrm{mV} /{ }^{\circ} \mathrm{C}$ & -76.0 & -76.0 & -100 \\
$\mathrm{KIP}$ & $\mathrm{mA} /{ }^{\circ} \mathrm{C}$ & 0.26 & 0.26 & 0.45 \\
KVP & $\mathrm{mV} /{ }^{\circ} \mathrm{C}$ & -76.0 & -76.0 & -100 \\
$\mathrm{NS}$ & - & 36 & 36 & 42 \\
\hline
\end{tabular}

TABLE 2: The statistical results for RTC France PV cell and Photowatt-PWP 201 PV module.

\begin{tabular}{lcccc}
\hline PV module & Parameters & Algorithm & Mean & SD \\
\hline SP75 & $n_{1}$ & DE & 1.041 & $6.899 E-4$ \\
SP75 & $n_{1}$ & IDE & 1.054 & $1.342 E-6$ \\
SP75 & $n_{2}$ & DE & 2.071 & 0.024 \\
SP75 & $n_{2}$ & IDE & 2.34 & 0.013 \\
SP75 & $R_{s}$ & DE & 0.405 & 0.009 \\
SP75 & $R_{s}$ & IDE & 0.331 & 0.006 \\
S25 & $n_{1}$ & DE & 1.031 & 0.002 \\
S25 & $n_{2}$ & IDE & 1.039 & 0.005 \\
S25 & $n_{2}$ & DE & 2.156 & 0.046 \\
S25 & $n_{2}$ & IDE & 2.257 & 0.034 \\
S25 & $R_{s}$ & DE & 0.779 & 0.013 \\
S25 & $R_{s}$ & IDE & 0.780 & 0.005 \\
ST36 & $n_{1}$ & DE & 1.643 & 0.080 \\
ST36 & $n_{1}$ & IDE & 1.679 & 0.082 \\
ST36 & $n_{2}$ & DE & 2.062 & 0.015 \\
ST36 & $n_{2}$ & IDE & 2.071 & 0.012 \\
ST36 & $R_{s}$ & DE & 1.258 & 0.010 \\
ST36 & $R_{s}$ & IDE & 1.347 & 0.009 \\
\hline
\end{tabular}

used in this paper can accurately solve the parameters of monocrystalline silicon components, polycrystalline silicon components, and thin film components. It can be seen from Table 6 that the average absolute value of SP75 monocrystalline silicon modules extracted by this method under STC is absolute. The error is 0.015 , the average absolute error of S25 polysilicon component under STC is 0.013 , the average absolute error of ST36 thin film component under STC is 0.026 , and the average absolute error is within 0.05 . The calculation results of the above three components are, respectively, obtained. Substituting (1), using the Newton iteration method, can solve the $I-V$ characteristic curve of PV modules under different temperatures and different light intensities as shown in Figures 4-9. It can be seen from the figures that the

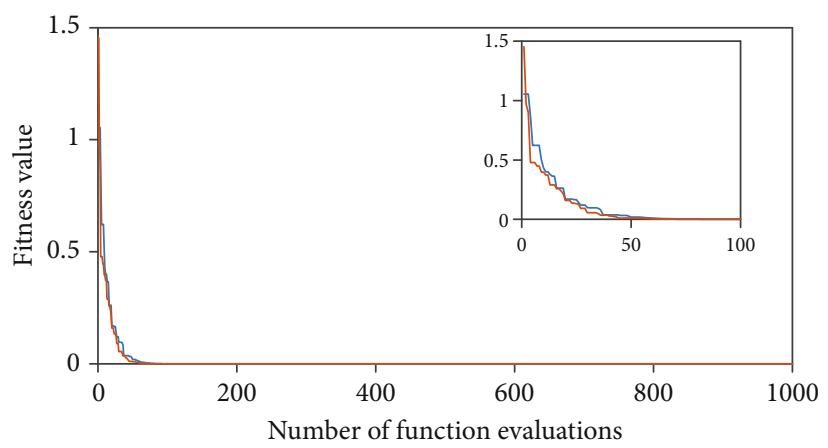

FIgURE 3: Convergence graph of the parameter optimization process using DE and IDE.

parameters extracted by the literature [28] and the proposed method under the STC can well fit the output $I-V$ characteristic curves of the three PV modules, but for the method proposed in this paper, the accuracy of the fitting is higher than that of the literature [28].

Set the absolute error $e_{1}$ to

$$
e_{1}=\left|I_{s, i}-I_{c, i}\right|,
$$

where $I_{s, i}$ is the experimental data and $I_{c, i}$ is the data obtained by simulation; the mean absolute error (MAE) expression is

$$
\begin{aligned}
\text { MAE } & =\frac{1}{N} \sum_{i=1}^{N}\left|e_{i}\right|, \\
\text { RMSE } & =\sqrt{\frac{1}{N} \sum_{i=1}^{N}\left(e_{i}\right)^{2},}
\end{aligned}
$$

where $N$ is the number of sampling points. The average absolute error of the photovoltaic modules in various environmental conditions is calculated according to equation (36) as shown in Table 6. It can be seen from the table that the average absolute error simulated by the parameters extracted by the proposed method under different environmental conditions is close to that of the literature [28], which proves the effectiveness of the proposed method.

With the CPU: Intel i5-4210U@2.39 GHz, memory: 12 GB computing environment, using the method proposed in this paper and the method of [28] to extract the two diodes of SP75, S25, and ST36 three photovoltaic modules under different environmental conditions, the time taken for the model parameters is shown in Table 7. It can be seen from the table that the time taken to extract parameters using this method in the same computing environment is smaller than that in the literature [28], indicating that the calculation speed can be improved after appropriate approximation.

Figures 10-12 shows the absolute error comparison of the parameters of three different modules under STC using the literature [28] and the extraction method of this paper. It can be seen from the figures that for the SP75 monocrystalline silicon module and the S25 polysilicon module, the absolute error of the two methods is basically the same in the 
TABLE 3: Extraction parameters of SP75 module with different methods.

\begin{tabular}{lccccccr}
\hline Method & $I_{\mathrm{pv}}(\mathrm{A})$ & $I_{o 1}(\mu \mathrm{A})$ & $I_{o 2}(\mu \mathrm{A})$ & $n_{1}$ & $n_{2}$ & $R_{s}(\Omega)$ & 0.394 \\
\hline $\mathrm{DE}$ & 4.80 & $6.33 E-10$ & $1.05 E-5$ & 1.042 & 2.059 & 633.93 \\
$\mathrm{IDE}$ & 4.80 & 0.15 & 0.40 & 1.36 & 2.37 & 0.320 & 383.11 \\
\hline
\end{tabular}

TABLE 4: Extraction parameters of S25 module with different methods.

\begin{tabular}{lccccccc}
\hline Method & $I_{\mathrm{pv}}(\mathrm{A})$ & $I_{o 1}(\mu \mathrm{A})$ & $I_{o 2}(\mu \mathrm{A})$ & $n_{1}$ & $n_{2}$ & $R_{s}(\Omega)$ & $R_{\mathrm{sh}}(\Omega)$ \\
\hline $\mathrm{DE}$ & 1.50 & $2.542 E-10$ & $1.687 E-6$ & 1.031 & 2.147 & 0.779 & 2672.8 \\
$\mathrm{IDE}$ & 1.50 & $1.043 E-3$ & $2.70 E-3$ & 1.097 & 2.239 & 0.833 & 1683.6 \\
\hline
\end{tabular}

TABLE 5: Extraction parameters of S25 module with different methods.

\begin{tabular}{lcccccrr}
\hline Method & $I_{\mathrm{pv}}(\mathrm{A})$ & $I_{o 1}(\mu \mathrm{A})$ & $I_{o 2}(\mu \mathrm{A})$ & $n_{1}$ & $n_{2}$ & $R_{s}(\Omega)$ & $R_{\mathrm{sh}}(\Omega)$ \\
\hline DE & 2.68 & $2.521 E+2$ & $6.53 E+2$ & 2.45 & 2.82 & 270.51 \\
$\mathrm{IDE}$ & 2.684 & $5.436 E-1$ & $8.40 E+1$ & 1.66 & 2.062 & 1.254 & 1044.6 \\
\hline
\end{tabular}

TABLE 6: Mean absolute error at different environmental conditions for three kinds of PV module.

\begin{tabular}{|c|c|c|c|c|}
\hline Method & Modules & Irradiance $\left(\mathrm{W} / \mathrm{m}^{2}\right)$ & Temperature $\left({ }^{\circ} \mathrm{C}\right)$ & MSE \\
\hline $\mathrm{DE}$ & SP75 & 1000 & 25 & 0.015 \\
\hline $\mathrm{DE}$ & SP75 & 600 & 25 & 0.023 \\
\hline $\mathrm{DE}$ & SP75 & 1000 & 20 & 0.039 \\
\hline $\mathrm{DE}$ & SP75 & 1000 & 60 & 0.063 \\
\hline IDE & SP75 & 1000 & 25 & 0.023 \\
\hline IDE & SP75 & 600 & 25 & 0.034 \\
\hline IDE & SP75 & 1000 & 20 & 0.139 \\
\hline IDE & SP75 & 1000 & 60 & 0.099 \\
\hline $\mathrm{DE}$ & S25 & 1000 & 25 & 0.013 \\
\hline $\mathrm{DE}$ & S25 & 600 & 25 & 0.011 \\
\hline $\mathrm{DE}$ & S25 & 1000 & 20 & 0.011 \\
\hline $\mathrm{DE}$ & S25 & 1000 & 60 & 0.018 \\
\hline IDE & S25 & 1000 & 25 & 0.012 \\
\hline IDE & S25 & 600 & 25 & 0.012 \\
\hline IDE & S25 & 1000 & 20 & 0.016 \\
\hline IDE & S25 & 1000 & 60 & 0.026 \\
\hline $\mathrm{DE}$ & ST36 & 1000 & 25 & 0.026 \\
\hline $\mathrm{DE}$ & ST36 & 600 & 25 & 0.011 \\
\hline $\mathrm{DE}$ & ST36 & 1000 & 20 & 0.031 \\
\hline $\mathrm{DE}$ & ST36 & 1000 & 60 & 0.019 \\
\hline IDE & ST36 & 1000 & 25 & 0.028 \\
\hline IDE & ST36 & 600 & 25 & 0.043 \\
\hline IDE & ST36 & 1000 & 20 & 0.034 \\
\hline IDE & ST36 & 1000 & 60 & 0.036 \\
\hline
\end{tabular}

constant current region of the photovoltaic module, but in the constant voltage region, the accuracy of the proposed method is higher than that of the literature [28] method. However, for the ST36 thin film module, the method of [28] is higher than the method proposed in this paper,

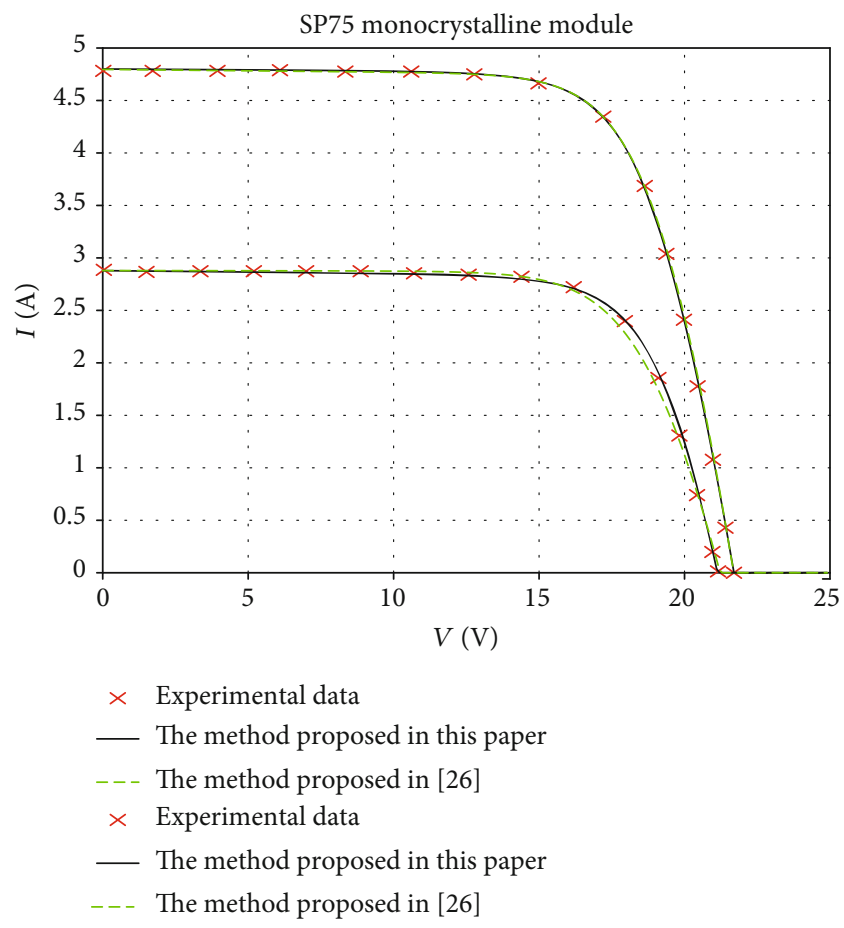

FIgURE 4: $I-V$ characteristics under varying irradiance for SP75 monocrystalline module $\left(T=25^{\circ} \mathrm{C}\right)$.

indicating that the conclusion of Yahya-Khotbehsara and Shahhoseini [44] for three to four times is not applicable to the thin film module.

\section{Conclusion}

This paper proposes a hybrid photovoltaic module parameter extraction algorithm that combines the analytical method with the improved differential evolution algorithm. It only needs four parameters that are the open-circuit voltage, short-circuit current, and maximum power point current 

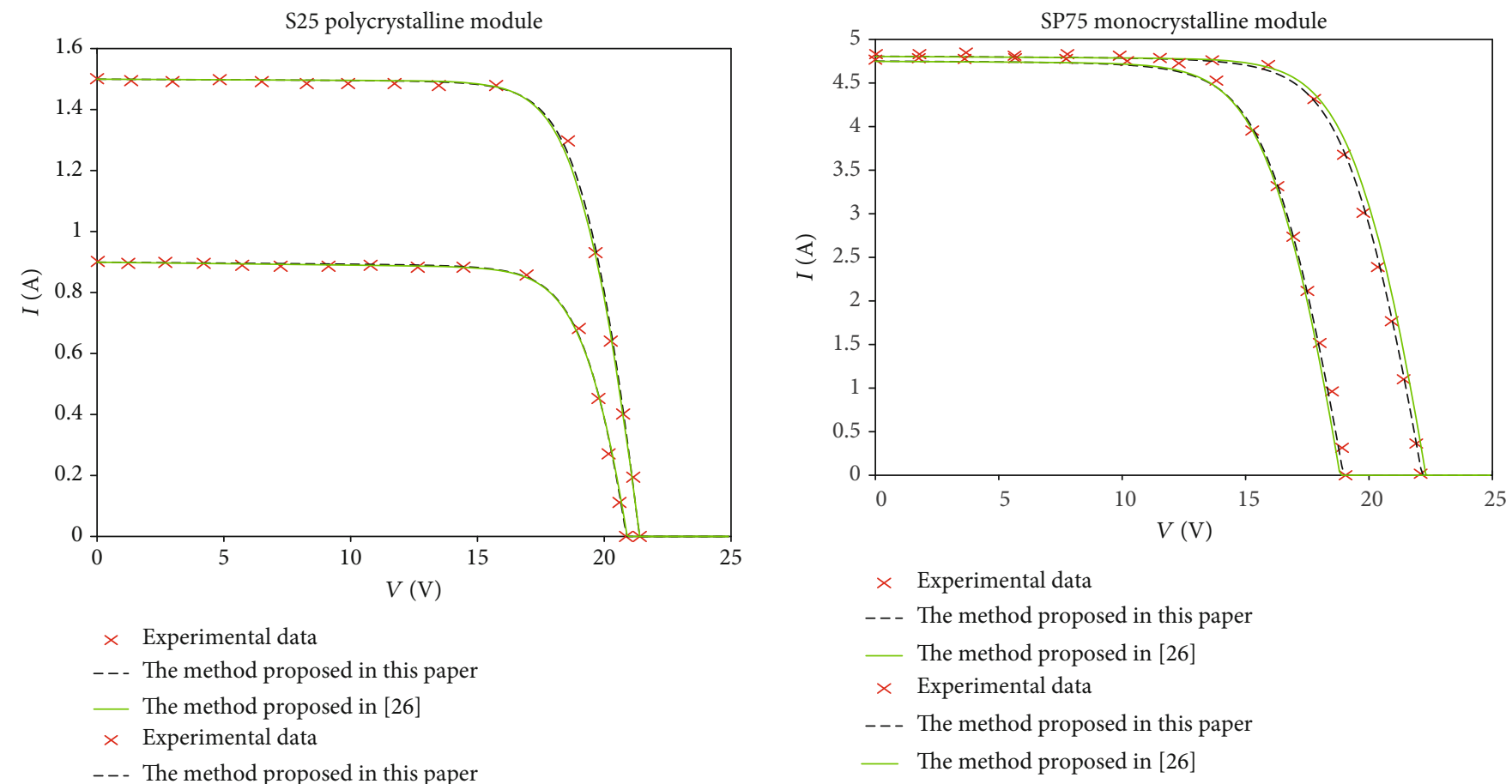

Figure 5: $I-V$ characteristics under varying irradiance for S25 polycrystalline module $\left(T=25^{\circ} \mathrm{C}\right)$.

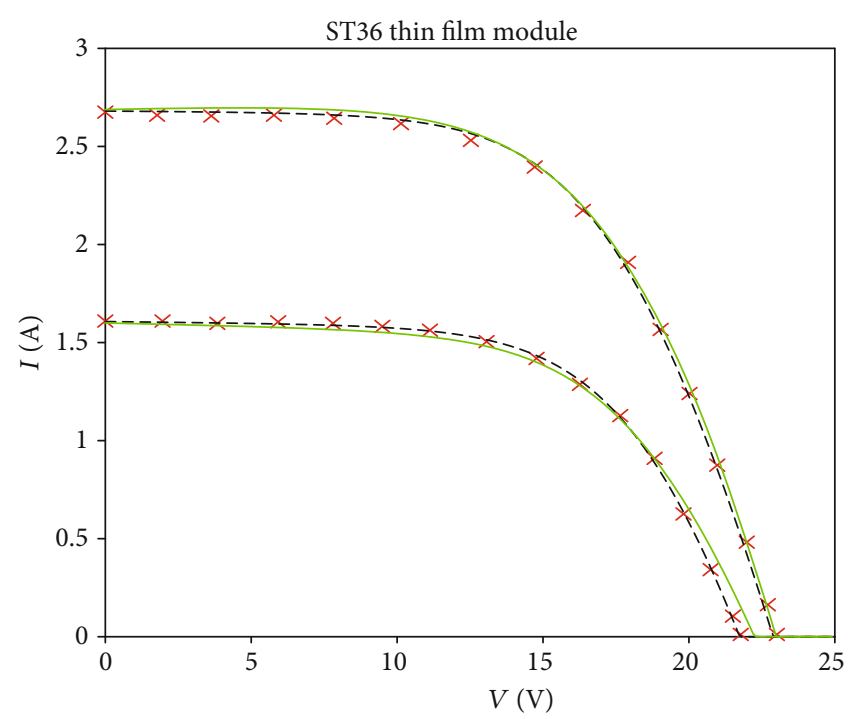

FIGURE 7: $I-V$ characteristics under varying temperature for SP75 monocrystalline module $\left(G=1000 \mathrm{~W} / \mathrm{m}^{2}\right)$.

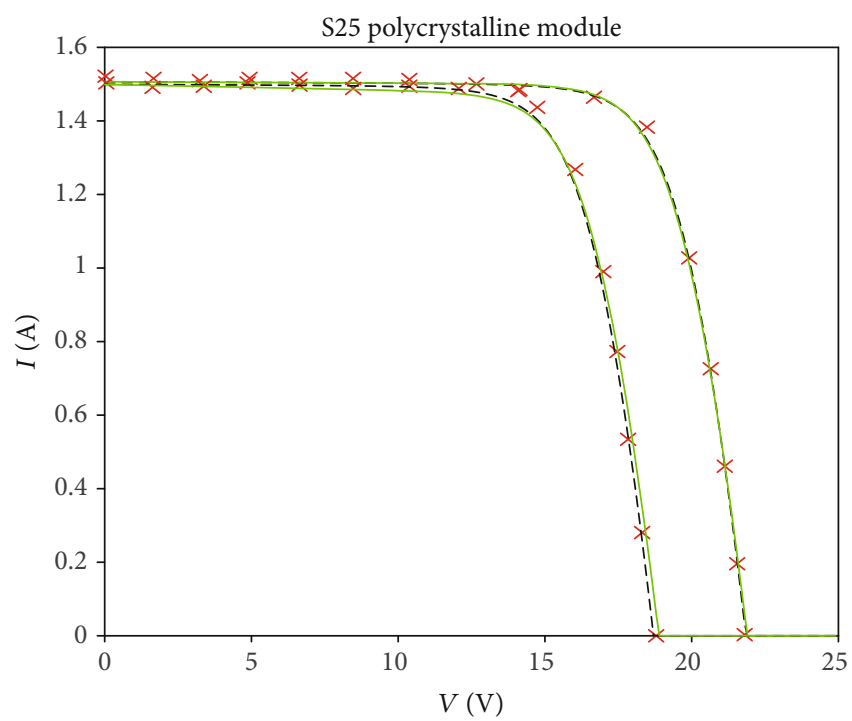

\footnotetext{
$\times$ Experimental data

- - - The method proposed in this paper

_ The method proposed in [26]

$\times$ Experimental data

- - The method proposed in this paper

- The method proposed in [26]
}

FIgURE 8: $I-V$ characteristics under varying temperature for S25 polycrystalline module $\left(G=1000 \mathrm{~W} / \mathrm{m}^{2}\right)$.

Figure 6: $I-V$ characteristics under varying irradiance for ST36 thin film module $\left(T=25^{\circ} \mathrm{C}\right)$. 


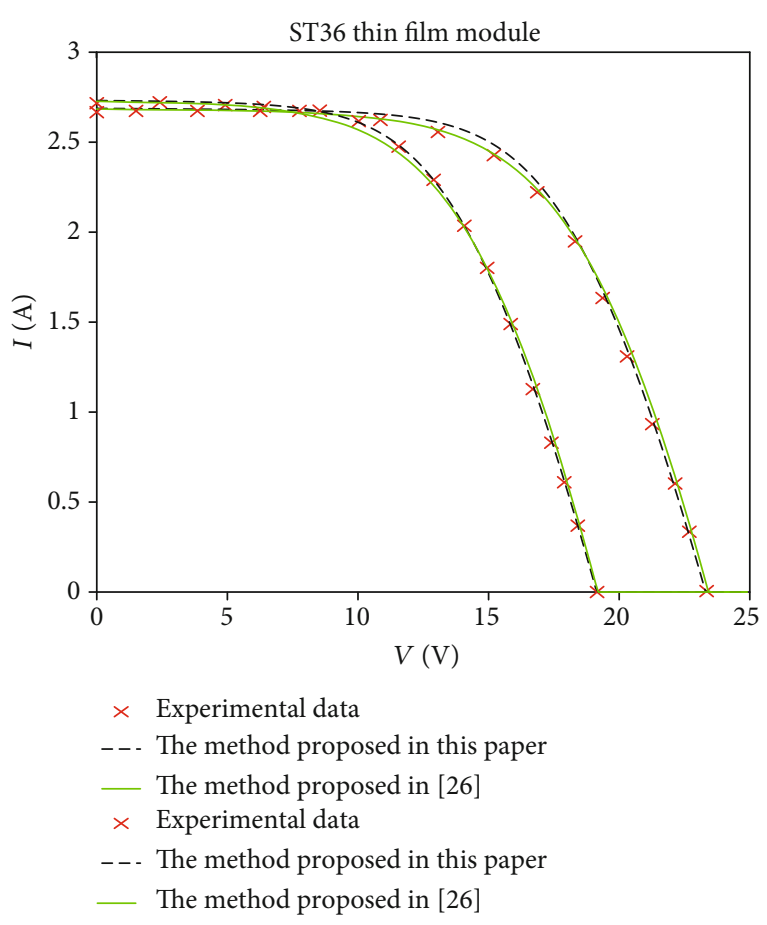

Figure 9: $I-V$ characteristics under varying temperature for ST36 thin film module $\left(G=1000 \mathrm{~W} / \mathrm{m}^{2}\right)$.

TABle 7: Time on extracting parameters from three kinds of PV modules by different methods.

\begin{tabular}{|c|c|c|c|c|}
\hline Method & Modules & $\begin{array}{c}\text { Irradiance } \\
\left(\mathrm{W} / \mathrm{m}^{2}\right)\end{array}$ & $\begin{array}{c}\text { Temperature } \\
\left({ }^{\circ} \mathrm{C}\right)\end{array}$ & $\begin{array}{l}\text { Time } \\
(\mathrm{ms})\end{array}$ \\
\hline $\mathrm{DE}$ & SP75 & 1000 & 25 & 2.845 \\
\hline $\mathrm{DE}$ & SP75 & 600 & 25 & 2.745 \\
\hline $\mathrm{DE}$ & SP75 & 1000 & 20 & 2.796 \\
\hline $\mathrm{DE}$ & SP75 & 1000 & 60 & 3.124 \\
\hline IDE & SP75 & 1000 & 25 & 1.975 \\
\hline IDE & SP75 & 600 & 25 & 1.854 \\
\hline IDE & SP75 & 1000 & 20 & 1.842 \\
\hline IDE & SP75 & 1000 & 60 & 2.026 \\
\hline $\mathrm{DE}$ & S25 & 1000 & 25 & 2.762 \\
\hline $\mathrm{DE}$ & S25 & 600 & 25 & 2.975 \\
\hline $\mathrm{DE}$ & S25 & 1000 & 20 & 2.874 \\
\hline $\mathrm{DE}$ & S25 & 1000 & 60 & 2.975 \\
\hline IDE & S25 & 1000 & 25 & 1.696 \\
\hline IDE & S25 & 600 & 25 & 1.852 \\
\hline IDE & S25 & 1000 & 20 & 1.796 \\
\hline IDE & S25 & 1000 & 60 & 1.927 \\
\hline $\mathrm{DE}$ & ST36 & 1000 & 25 & 2.951 \\
\hline $\mathrm{DE}$ & ST36 & 600 & 25 & 3.246 \\
\hline $\mathrm{DE}$ & ST36 & 1000 & 20 & 2.987 \\
\hline $\mathrm{DE}$ & ST36 & 1000 & 60 & 2.994 \\
\hline IDE & ST36 & 1000 & 25 & 1.786 \\
\hline IDE & ST36 & 600 & 25 & 1.954 \\
\hline IDE & ST36 & 1000 & 20 & 1.997 \\
\hline IDE & ST36 & 1000 & 60 & 1.849 \\
\hline
\end{tabular}

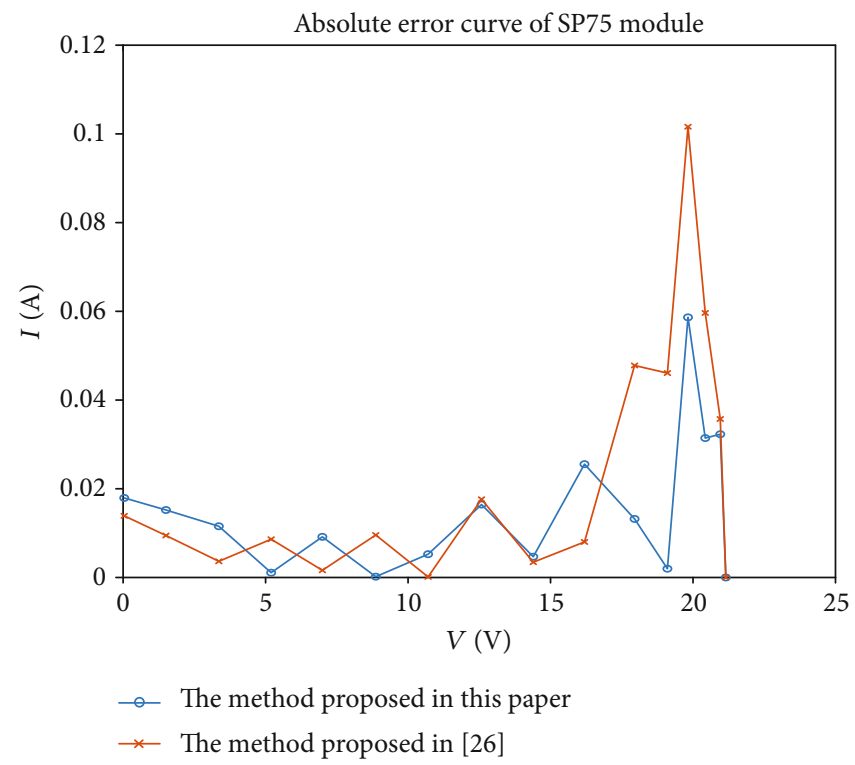

FIGURE 10: Absolute error comparison of SP75 modules with different extraction methods under STC.

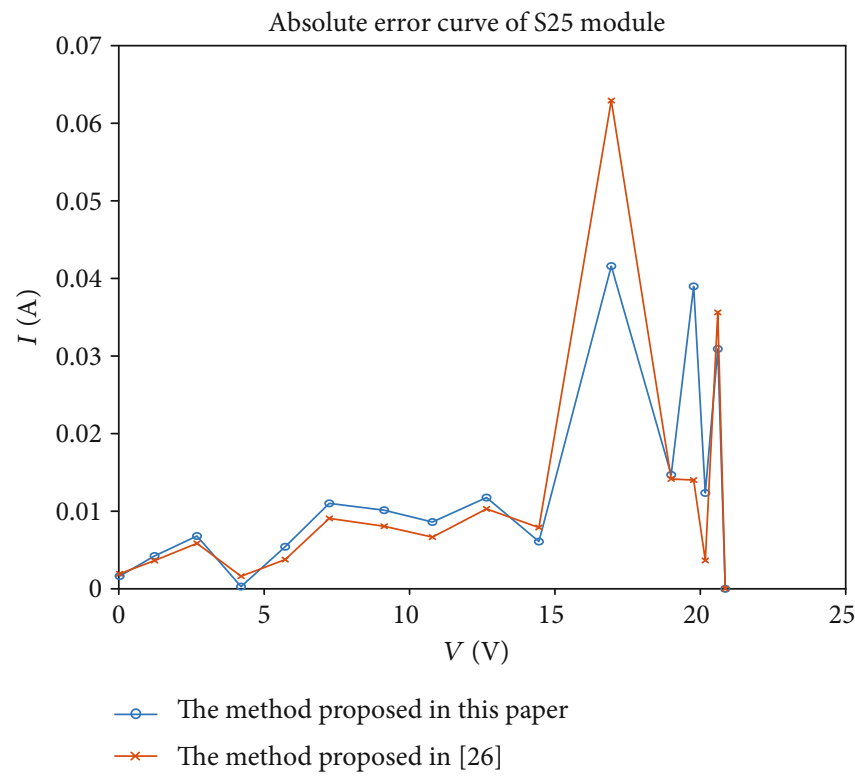

FIgURE 11: Absolute error comparison of S25 module with different extraction methods under STC.

and voltage of the photovoltaic module provided by the manufacturer; then, the parameters of the photovoltaic module based on the dual-diode equivalent circuit model are extracted. In the proposed algorithm, the equivalent circuit model is simplified by the analytical method to improve the efficiency of the algorithm. Then, the adaptive algorithm is used to adjust the parameters in the differential evolution algorithm to avoid the algorithm falling into local optimum and improve the convergence speed. In this paper, a comprehensive experimental test is carried out on the algorithm to study the performance of the algorithm on the parameter extraction of different types of photovoltaic modules. 


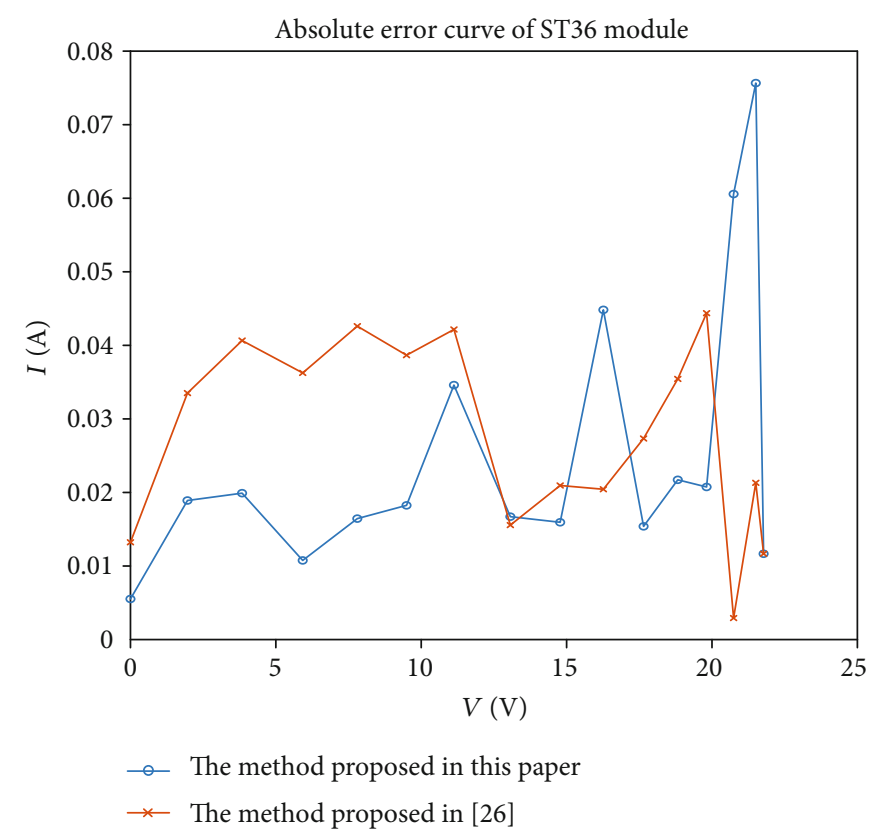

FIGURE 12: Absolute error comparison of ST36 modules with different extraction methods under STC.

Compared with other recent methods, experimental and statistical analysis proves the superiority of the proposed algorithm in terms of accuracy, reliability, and computational efficiency.

\section{Data Availability}

The experimental data used to support the findings of this study are included within the article.

\section{Conflicts of Interest}

The authors declare no conflict of interest.

\section{Authors' Contributions}

H.W. and Z.S. conceived the paper and designed and performed the simulations; H.W. wrote and revised the paper; H.W. and Z.S. finally analyzed the data.

\section{Acknowledgments}

This research was supported by the Special Financial Aid to Post-Doctor Research Fellow in Chongqing (grant Xm2014086); Science and Technology Research Project of the Chongqing Municipal Education Commission (grant KJ131321), and Science and Technology Research Project of Yangtze Normal University (grant 2013XJ2D004).

\section{References}

[1] J. Fan, L. Wu, F. Zhang, H. Cai, X. Ma, and H. Bai, "Evaluation and development of empirical models for estimating daily and monthly mean daily diffuse horizontal solar radiation for different climatic regions of China," Renewable and Sustainable Energy Reviews, vol. 105, pp. 168-186, 2019.
[2] L. Wu, G. Huang, J. Fan, F. Zhang, X. Wang, and W. Zeng, "Potential of kernel-based nonlinear extension of Arps decline model and gradient boosting with categorical features support for predicting daily global solar radiation in humid regions," Energy Conversion and Management, vol. 183, pp. 280-295, 2019.

[3] J. Fan, L. Wu, F. Zhang et al., "Empirical and machine learning models for predicting daily global solar radiation from sunshine duration: a review and case study in China," Renewable and Sustainable Energy Reviews, vol. 100, pp. 186-212, 2019.

[4] J. Fan, X. Wang, L. Wu et al., "New combined models for estimating daily global solar radiation based on sunshine duration in humid regions: a case study in South China," Energy Conversion and Management, vol. 156, pp. 618-625, 2018.

[5] J. Fan, B. Chen, L. Wu, F. Zhang, X. Lu, and Y. Xiang, "Evaluation and development of temperature-based empirical models for estimating daily global solar radiation in humid regions," Energy, vol. 144, pp. 903-914, 2018.

[6] F. Harrou, B. Taghezouit, and Y. Sun, "Robust and flexible strategy for fault detection in grid-connected photovoltaic systems," Energy Conversion and Management, vol. 180, pp. 1153-1166, 2019.

[7] L. Chen and X. Wang, "Adaptive fault localization in photovoltaic systems," IEEE Transactions on Smart Grid, vol. 9, no. 6, pp. 6752-6763, 2018.

[8] K. Jia, C. Gu, Z. Xuan, L. Li, and Y. Lin, "Fault characteristics analysis and line protection design within a large-scale photovoltaic power plant," IEEE Transactions on Smart Grid, vol. 9, no. 5, pp. 4099-4108, 2018.

[9] J. D. Bastidas-Rodriguez, E. Franco, G. Petrone, C. A. Ramos-Paja, and G. Spagnuolo, "Quantification of photovoltaic module degradation using model based indicators," Mathematics and Computers in Simulation, vol. 131, pp. 101-113, 2017.

[10] K. A. Kim, G. S. Seo, B. H. Cho, and P. T. Krein, "Photovoltaic hot-spot detection for solar panel substrings using AC parameter characterization," IEEE Transactions on Power Electronics, vol. 31, no. 2, pp. 1121-1130, 2016.

[11] T. Easwarakhanthan, J. Bottin, A. El-Slassi, R. Ravelet, and S. Ravelet, "Microcomputer-controlled simulator of a photovoltaic generator using a programmable voltage generator," Solar Cells, vol. 17, no. 2-3, pp. 383-390, 1986.

[12] Z. Zhong-Zheng and C. Xiao-Fang, "Dual-origin coordinate system for solar cells," Acta Physica Sinica, vol. 63, no. 11, 2014.

[13] R. Abbassi, A. Abbassi, A. A. Heidari, and S. Mirjalili, "An efficient salp swarm-inspired algorithm for parameters identification of photovoltaic cell models," Energy Conversion and Management, vol. 179, pp. 362-372, 2019.

[14] M. G. Villalva, J. R. Gazoli, and E. Ruppert Filho, "Comprehensive approach to modeling and simulation of photovoltaic arrays," IEEE Transactions on Power Electronics, vol. 24, no. 5, pp. 1198-1208, 2009.

[15] J.-P. Charles, I. Mekkaoui-Alaoui, G. Bordure, and P. Mialhe, "A critical study of the effectiveness of the single and double exponential models for I-V characterization of solar cells," Solid State Electronics, vol. 28, no. 8, pp. 807820, 1985.

[16] B. C. Babu and S. Gurjar, "A novel simplified two-diode model of photovoltaic (PV) module," IEEE Journal of Photovoltaics, vol. 4, no. 4, pp. 1156-1161, 2014. 
[17] A. A. Elbaset, H. Ali, and M. Abd-El Sattar, "Novel sevenparameter model for photovoltaic modules," Solar Energy Materials and Solar Cells, vol. 130, pp. 442-455, 2014.

[18] K. Ishaque, Z. Salam, and H. Taheri, "Simple, fast and accurate two-diode model for photovoltaic modules," Solar Energy Materials and Solar Cells, vol. 95, no. 2, pp. 586-594, 2011.

[19] Y. Wang, S. Yize, P. Lele, and Y. Xu, "Parameter extraction for photovoltaic module based on Lambert W function," Acta Physica Sinica, vol. 61, no. 24, pp. 533-538, 2012.

[20] K. Ishaque, Z. Salam, H. Taheri, and A. Shamsudin, "A critical evaluation of EA computational methods for photovoltaic cell parameter extraction based on two diode model," Solar Energy, vol. 85, no. 9, pp. 1768-1779, 2011.

[21] L. Guo, Z. Meng, Y. Sun, and L. Wang, "Parameter identification and sensitivity analysis of solar cell models with cat swarm optimization algorithm," Energy Conversion and Management, vol. 108, pp. 520-528, 2016.

[22] D. H. Muhsen, A. B. Ghazali, T. Khatib, and I. A. Abed, "Parameters extraction of double diode photovoltaic module's model based on hybrid evolutionary algorithm," Energy Conversion and Management, vol. 105, pp. 552-561, 2015.

[23] X. Chen, B. Xu, C. Mei, Y. Ding, and K. Li, "Teachinglearning-based artificial bee colony for solar photovoltaic parameter estimation," Applied Energy, vol. 212, pp. 15781588, 2018.

[24] G. Xiankun, Y. Chuanan, G. Xiangchuan, and Y. Yongchang, "Accuracy comparison between implicit and explicitsinglediode models of photovoltaic cells and modules," Acta Physica Sinica, vol. 63, no. 17, pp. 366-375, 2012.

[25] X. Chen and K. Yu, "Hybridizing cuckoo search algorithm with biogeography-based optimization for estimating photovoltaic model parameters," Solar Energy, vol. 180, pp. 192206, 2019.

[26] K. Yu, B. Qu, C. Yue, S. Ge, X. Chen, and J. Liang, “A performance-guided JAYA algorithm for parameters identification of photovoltaic cell and module," Applied Energy, vol. 237, pp. 241-257, 2019.

[27] K. Yu, J. J. Liang, B. Y. Qu, Z. Cheng, and H. Wang, "Multiple learning backtracking search algorithm for estimating parameters of photovoltaic models," Applied Energy, vol. 226, pp. 408-422, 2018.

[28] V. J. Chin, Z. Salam, and K. Ishaque, "An accurate and fast computational algorithm for the two-diode model of PV module based on a hybrid method," IEEE Transactions on Industrial Electronics, vol. 64, no. 8, pp. 6212-6222, 2017.

[29] W. Tao, J. Xianzhong, Y. Huaiqiao, and G. Qiang, “Application of adaptive differential evolution algorithm in parameter identification of photovoltaic module model," Electric Power Science and Engineering, vol. 34, no. 4, pp. 1-7, 2018.

[30] A. K. Qin, V. L. Huang, and P. N. Suganthan, "Differential evolution algorithm with strategy adaptation for global numerical optimization," IEEE Transactions on Evolutionary Computation, vol. 13, no. 2, pp. 398-417, 2009.

[31] T. Vo-Duy, V. Ho-Huu, H. Dang-Trung, and T. Nguyen-Thoi, "A two-step approach for damage detection in laminated composite structures using modal strain energy method and an improved differential evolution algorithm," Composite Structures, vol. 147, pp. 42-53, 2016.

[32] J. Tvrdik and I. Krivy, "Hybrid differential evolution algorithm for optimal clustering," Applied Soft Computing, vol. 35, pp. 502-512, 2015.
[33] H. V. H. Ayala, L. dos Santos Coelho, V. C. Mariani, and A. Askarzadeh, "An improved free search differential evolution algorithm: a case study on parameters identification of one diode equivalent circuit of a solar cell module," Energy, vol. 93, pp. 1515-1522, 2015.

[34] A. K. Qin and P. N. Suganthan, "Self-adaptive differential evolution algorithm for numerical optimization," in 2005 IEEE Congress on Evolutionary Computation 2005 IEEE Congress on Evolutionary Computation, pp. 1785-1791, 2005.

[35] P. Civicioglu and E. Besdok, "Bernstain-search differential evolution algorithm for numerical function optimization," Expert Systems with Applications, vol. 138, p. 112831, 2019.

[36] W. He, W. Gong, L. Wang, X. Yan, and C. Hu, "Fuzzy neighborhood-based differential evolution with orientation for nonlinear equation systems," Knowledge-Based Systems, vol. 182, p. 104796, 2019.

[37] F. Caraffini, A. V. Kononova, and D. Corne, "Infeasibility and structural bias in differential evolution," Information Sciences, vol. 496, pp. 161-179, 2019.

[38] M. Tian and X. Gao, "Differential evolution with neighborhood-based adaptive evolution mechanism for numerical optimization," Information Sciences, vol. 478, pp. 422-448, 2019.

[39] G. Wu, X. Shen, H. Li, H. Chen, A. Lin, and P. N. Suganthan, "Ensemble of differential evolution variants," Information Sciences, vol. 423, pp. 172-186, 2018.

[40] E. H. de Vasconcelos Segundo, A. L. Amoroso, V. C. Mariani, and L. D. S. Coelho, "Economic optimization design for shelland-tube heat exchangers by a Tsallis differential evolution," Applied Thermal Engineering, vol. 111, pp. 143-151, 2017.

[41] H. V. Hultmann Ayala, F. M. Dos Santos, V. C. Mariani, and L. D. S. Coelho, "Image thresholding segmentation based on a novel beta differential evolution approach," Expert Systems with Applications, vol. 42, no. 4, pp. 2136-2142, 2015.

[42] L. D. S. Coelho, R. C. Thom Souza, and V. C. Mariani, "Improved differential evolution approach based on cultural algorithm and diversity measure applied to solve economic load dispatch problems," Mathematics and Computers in Simulation, vol. 79, no. 10, pp. 3136-3147, 2009.

[43] S. Prabha and R. Yadav, "Differential evolution with biological-based mutation operator," Engineering Science and Technology, an International Journal, 2019.

[44] A. Yahya-Khotbehsara and A. Shahhoseini, "A fast modeling of the double-diode model for PV modules using combined analytical and numerical approach," Solar Energy, vol. 162, pp. 403-409, 2018.

[45] J. Zhang and A. C. Sanderson, "JADE: adaptive differential evolution with optional external archive," IEEE Transactions on Evolutionary Computation, vol. 13, no. 5, pp. 945-958, 2009. 

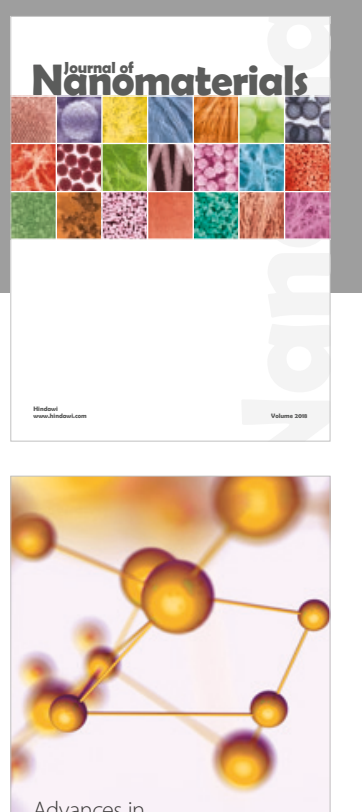

Physical Chemistry
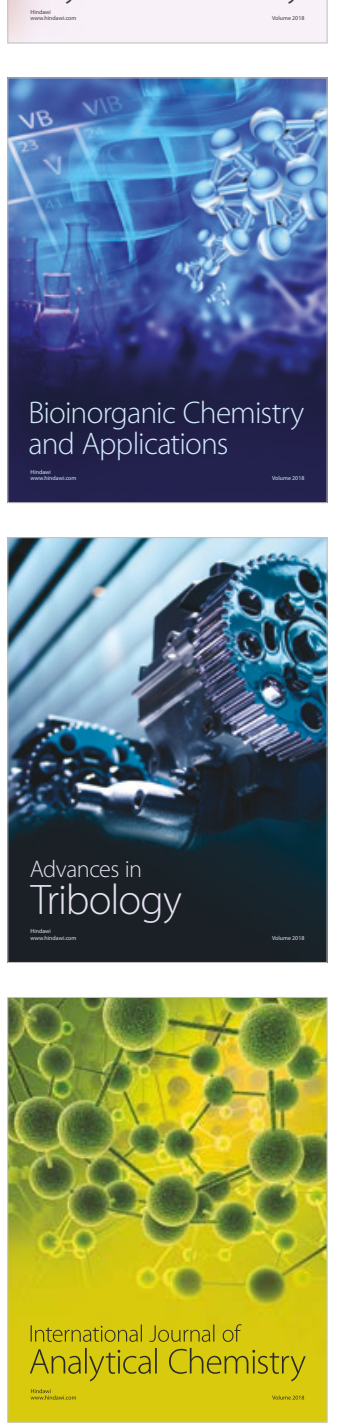

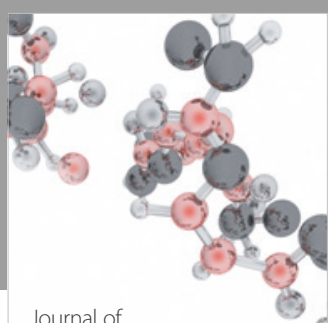

Analytical Methods

in Chemistry

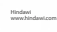

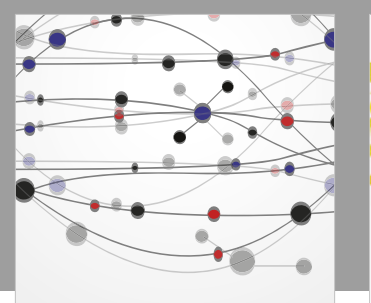

The Scientific World Journal

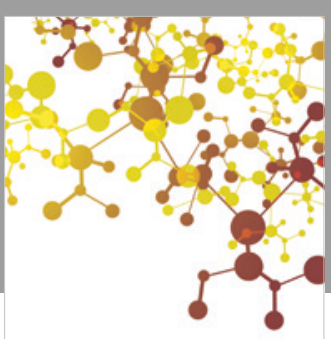

Journal of

Applied Chemistry
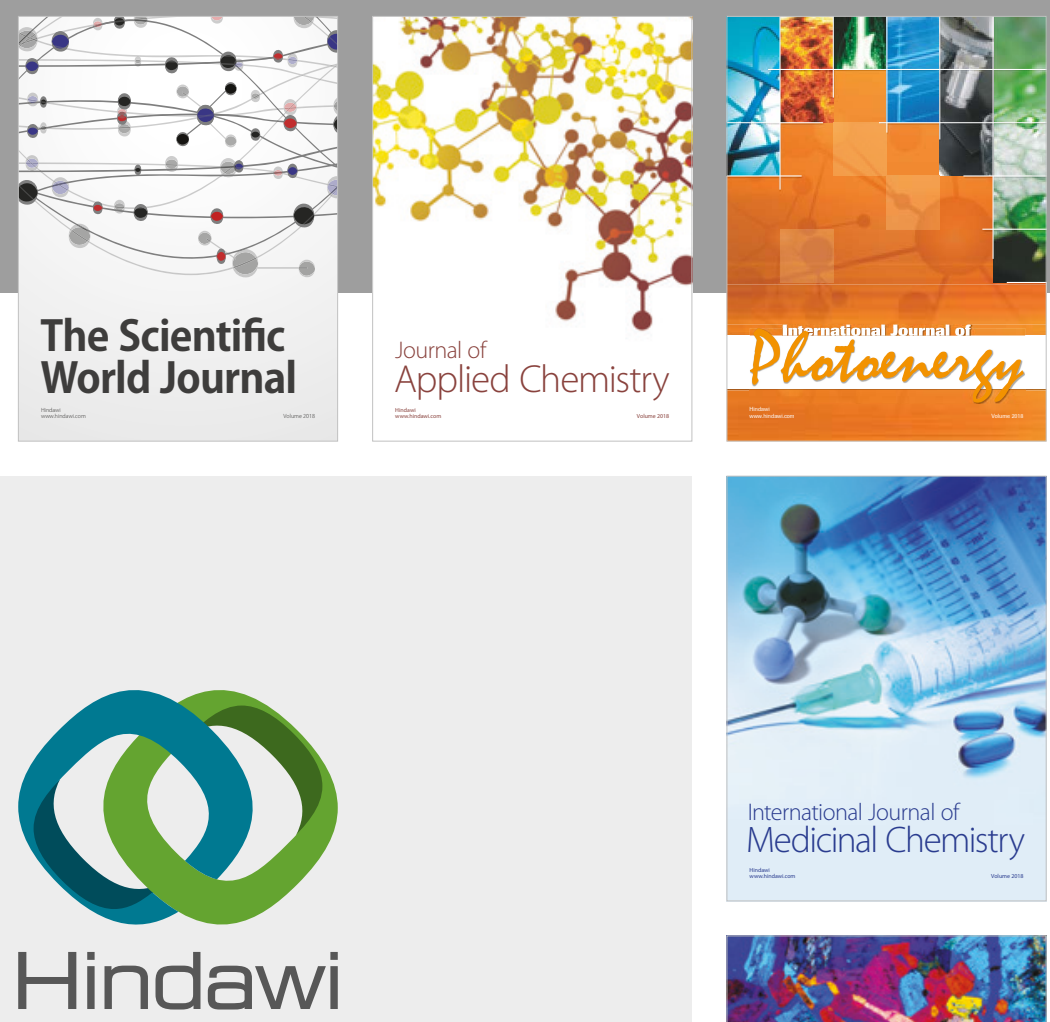

Submit your manuscripts at

www.hindawi.com
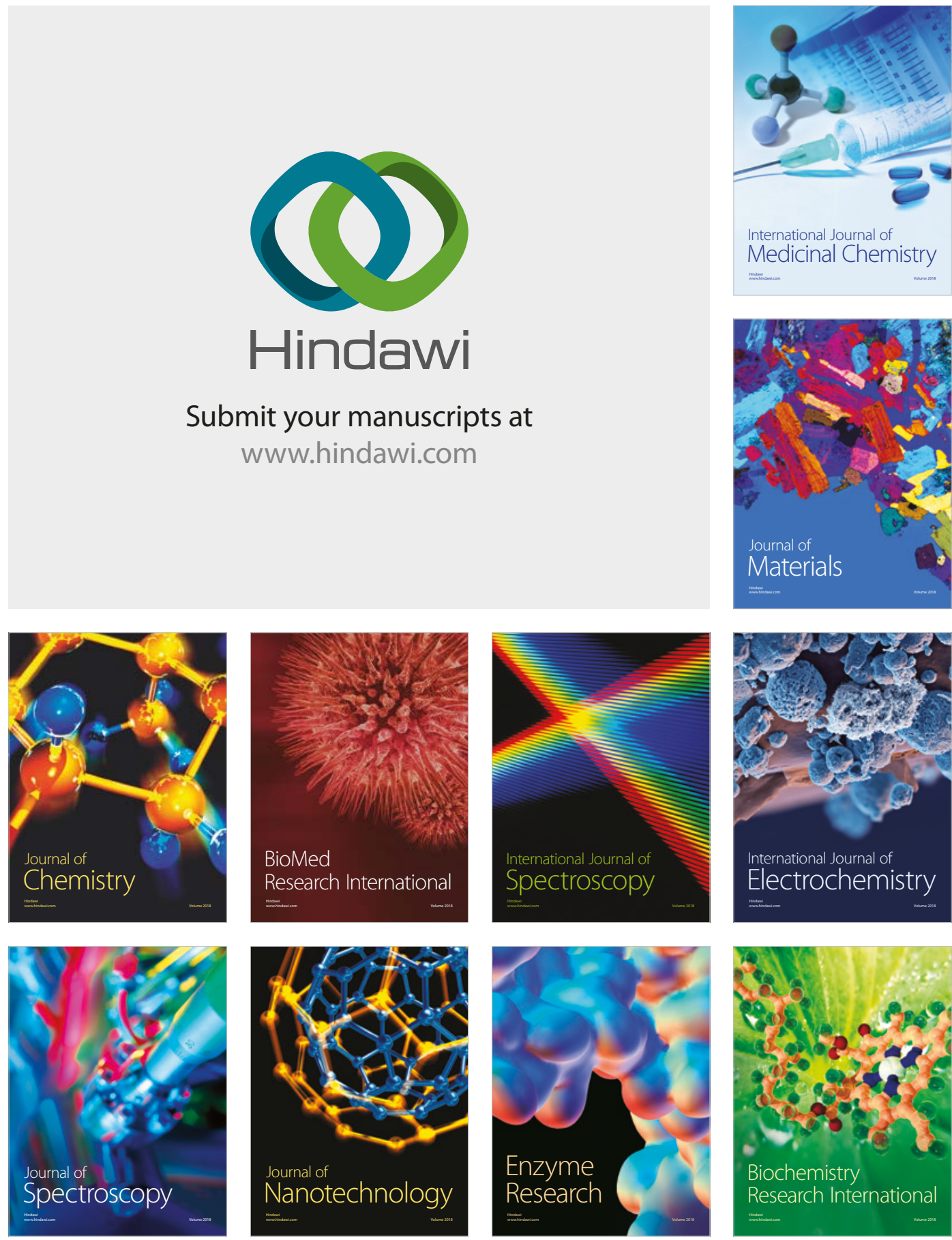
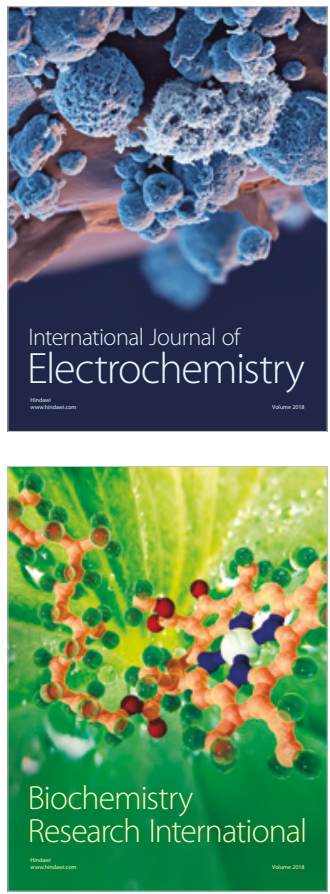